\title{
ASD Repair in Adolescent and Adult Patients, and Establishing a Heart Team in Low-Volume Centres: Should it be the Current Standard of Care?
}

\author{
Amjad Bani Hani ${ }^{1}$, Kareem Salhiyyah ${ }^{2}$, Mohammad Hasan Salameh ${ }^{1}$, Mahmoud
} Abu-Abeleh ${ }^{1}$, moaath alsmady ${ }^{1}$, Hala Abu Fares ${ }^{1}$, Mohammad Al Rawashdeh ${ }^{1}$, and Iyad Al-Ammouri ${ }^{1}$

${ }^{1}$ The University of Jordan

${ }^{2}$ Affiliation not available

April 17, 2021

\begin{abstract}
Objectives: A retrospective review of adolescent and adult patients with Atrial Septal Defect (Secundum ASD) who underwent secundum ASD closure by transcatheter closure (TCC) or surgery at Jordan University Hospital (JUH). We seek to illustrate the importance of a multidisciplinary Heart Team in low-volume centres, and report the experience and outcomes of this approach. Methodology: A retrospective observational study of 42 patients who underwent secundum ASD closure by TCC or surgery at JUH. We utilised the hospital's electronic record system to attain patients' information, and SPSS and Microsoft Excel were used to analyse the data. Results: 42 patients with secundum ASD were treated during the period between January 2015 and December 2019. The mean age of participants was 34.1 ( \pm 14.3). A total of 34 patients underwent TCC, seven surgical closure, and one a hybrid approach. There were no incidents of mortality, but two minor morbidities were reported. After an average follow-up period of 13.2-/ +13.6 months, with a range of 1-47 months, most patients experienced an improvement in their symptoms. There was also a significant reduction of the right ventricular dimension: Conclusion: A Heart Team approach is necessary as the use of minimally invasive cardiac surgery MICS and Transcatheter closure TCC continues to advance. A Heart Team provides patients with a variety of safe and cosmetic solutions that facilitate rapid management and recovery by encouraging the merits and avoiding the complications of each modality. Ultimately, the Heart Team allows low-volume centres to achieve excellent outcomes.
\end{abstract}

\section{Hosted file}

Manuscript ASD PDF.pdf available at https://authorea.com/users/408437/articles/518447-asdrepair-in-adolescent-and-adult-patients-and-establishing-a-heart-team-in-low-volumecentres-should-it-be-the-current-standard-of-care

\section{Hosted file}

Tables PDF.pdf available at https://authorea.com/users/408437/articles/518447-asd-repairin-adolescent-and-adult-patients-and-establishing-a-heart-team-in-low-volume-centresshould-it-be-the-current-standard-of-care 